\title{
Numerical Simulation for Non-Metallic Particles Air Sorting with EDEM-FLUENT
}

\author{
Chenze Man, Chaobin Hu, Guohong Dai* \\ Changshu Institute of Technology \\ Jiangsu Key Laboratory of Recycling and Reusing Technology for Mechanical and Electronic Products \\ Changshu, China \\ manjianwei01@163.com, superhcb@163.com, * *dgh@cslg.cn
}

\begin{abstract}
In the recycling of end of life vehicle, the residue of shredder composed of metal particles and non-metal particles. If non-metal particles is sorted into raw material with high purity, the recycling value of end of life vehicle will be increased. Due to the litter differences in the volume of solid particles after the broken, the use of traditional hole screening is difficult to achieve separation. According to the different of particle density, they can be separated by wind blowing. For single layer particles group theory mathematics formula can describe the trajectory of particle motion more accurately, but for a certain thickness of the granular layer, due to the interference of particle swarm to the flow field, single particle theory formula for sorting is not accurate. For seeking the optimal kinematic parameters (wind speed, angle direction, wind chamber size etc.), in order to achieve the maximum efficiency of winnowing, Through the coupling of the EDEM-FLUENT software conduct numerical simulation of the air separation process, using control variable method, choose the best separation method. In the analysis of two kinds of rubber and glass particles, when the wind speed is $12 \mathrm{~m} / \mathrm{s}$, wind angle is 20 degrees, the maximum separation efficiency can be obtained.
\end{abstract}

Keywords—sorting; ELV; recycling; sustainable development

\section{INTRODUCTION}

\section{A. Basic method of the experiment}

Size differences of solid particles can be separation by sieving, for basically the same shape of the particles can be separation by density method of winnowing. At present, the domestic and foreign scholars have done many researches on these methods, most of which get the best sorting parameters through the analysis of the particle motion equation [1][2]. Because of the interference of the particle swarm to the flow field, and the interaction of particle to particle, it is difficult to get more accurate results by mathematical calculation. In this paper, through EDEM and FLUENT coupling simulation experiment, analyses the difference of the distance between two kinds of particles in the collecting groove to get the best parameters of wind separation.

\section{B. Calculation model of software}

DEM-FLUENT coupling uses an improved free drag to calculate the force acting on a spherical particle. For the case of non- spherical surface particles, using spherical bounding box resistance to calculate the resistance. All of the fluid parameters are derived from the CFD grid cell, which contains the center of the EDEM particles. [3]Therefore, this treatment method is only suitable for the treatment of two cases of particles: (1) Particles that are of the same size or size smaller than the fluid grid cells. (2) The variation of the parameters (velocity, density and viscosity) of the fluid around the particles is essentially constant. The drag coefficient $C_{D}$ is dependent on the Reynolds number $R_{e}$.

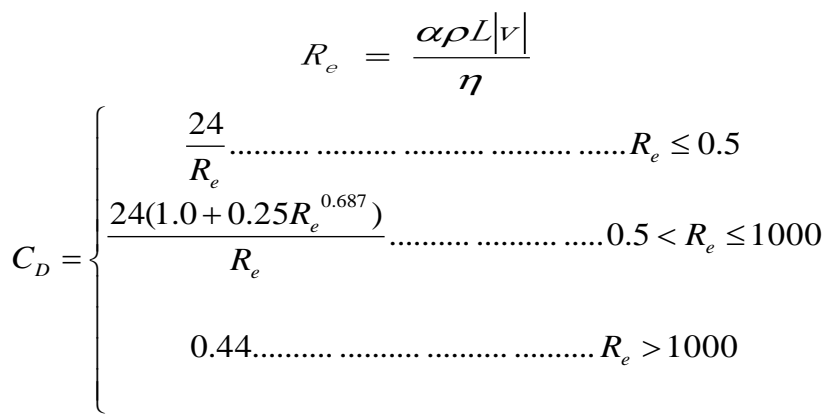

$$
\begin{aligned}
& \text { Where } \rho \text { is fluid density, } \\
& \eta \text { is viscosity, } \\
& L \text { is diameter of the particles bounding sphere, } \\
& v \text { is relative velocity between the fluid and the particle. }
\end{aligned}
$$

\section{KINEMATICS ANALYSIS OF WIND SEPARATION EQUIPMENT}

The kinematic parameters of wind separation equipment has great effect on the efficiency of wind separation, so determine the optimal parameters has important significance.

The particles enter the flow field with a horizontal initial velocity $v_{0}$, and the particles are subjected to gravity $\boldsymbol{G}$, mass $m$, airflow velocity $v$, and flow resistance[3]

$$
\begin{gathered}
F=C_{d} \frac{\rho_{f} v_{r}{ }^{2}}{2} S . \\
\text { Where } C_{d} \text { is flow coefficient, } \\
\rho_{f} \text { is Air density, }
\end{gathered}
$$


Denote relative velocity of particles and wind by $v_{r}$,

Denote the frontal area of particles by $S$

The movement of the particles in the horizontal direction can be obtained as follows:

$$
x=v \cos \beta t-\frac{m}{\Delta} \ln \left(\frac{m}{\Delta t\left(v \cos \beta-v_{0}\right)+m}\right)
$$

Where $\Delta=C_{d} \frac{\rho_{f} S}{2}$,

$\beta$ is wind angle,

$t$ is material movement time.

The equations of motion of particles in the vertical direction are

$$
y=\frac{m}{\Delta} \ln \frac{\left(\sqrt{\frac{m g}{\Delta}}+v \sin \beta\right) e^{\sqrt{\frac{\Delta g}{m}} t}+\left(\sqrt{\frac{m g}{\Delta}}-v \sin \beta\right) e^{-\sqrt{\frac{\Delta g}{m}} t}}{2 \sqrt{\frac{m g}{\Delta}}}
$$

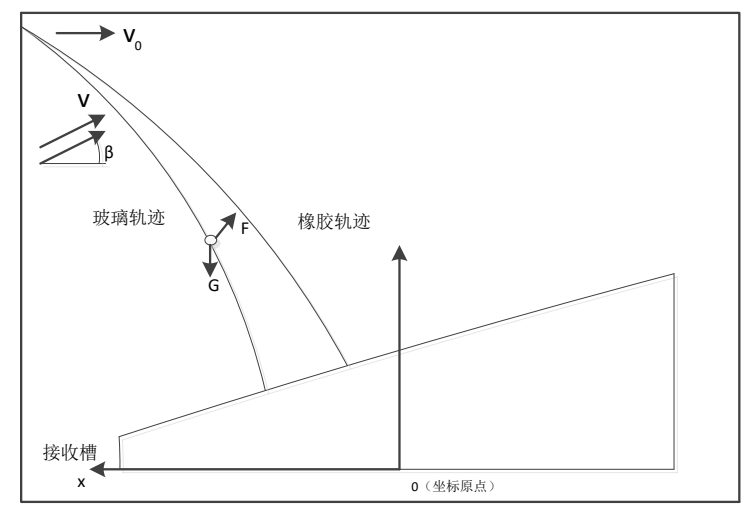

$v_{0}$-Horizontal initial velocity; $\mathcal{V}$-wind speed; $\boldsymbol{\beta}$-wind angle; $\boldsymbol{G}$-gravity; $\boldsymbol{F}$-air drag force

Fig. 1 Schematic diagram of winnowing device.

Different weight of two kinds of particles (rubber and glass) with a certain initial velocity into the winnowing room and winnowing room has the wind of certain oblique angle and speed blowing particles. Different mass of particles are subjected to are subjected to the different air drag force, In the case of a certain vertical distance will produce different horizontal distance, so be able to achieve the purpose of sorting . Import the length, the width, the height of $4000 \times$ $2000 \mathrm{~mm} \times 500 \mathrm{~mm}$ rectangular block into EDEM software to simulate the entire winnowing region, At the bottom of the flow field, the ladder type collecting tank is used to collect the statistics of solid particles.. Figure 1 is a diagram of mechanism of air separation equipment.

\section{SIMULATION PARAMETERS}

EDEM Modeling based on spherical particles fills to reduce simulation time and computation. The two particles are defined as radius $4 \mathrm{~mm}$, contact radius $4 \mathrm{~mm}$ round ball shape. [5][6] Contact coefficient of between the various materials as shown in table 1 .

\begin{tabular}{|c|c|c|c|}
\hline & Glass & Rubber & Steel \\
\hline Glass & $0.9,0.1,0.01$ & $0.3,0.3,0.01$ & $\begin{array}{lll}0.5, & 0.5, & 0.01\end{array}$ \\
\hline Rubber & & $0.3,0.3,0.01$ & $0.3,0.3,0.01$ \\
\hline
\end{tabular}

TABLE 1 CONTACT PARAMETERS OF EACH MATERIAL IN EDEM friction

$e$-Coefficient of restitution; $\boldsymbol{f}_{1}$-coefficient of static friction; $\boldsymbol{f}_{2}$-coefficient of rolling

The initial velocity of particles is $1 \mathrm{~m} / \mathrm{s}$, the total height of the particle falling into collecting tank is $3 \mathrm{~m}$. Establishing a $200 \mathrm{~mm} \times 50 \mathrm{~mm}$ particle factory plane used to define the initial entrance of the particle, the total numbers of the two kinds of particles are 2000, the production rate of particles is 5000 per second. The physical parameters of each particle material required for the simulation are shown in Table 2.

TABLE 2 PHYSICAL PARAMETERS OF EACH MATERIAL IN EDEM

\begin{tabular}{|c|c|c|c|}
\hline Material & $\begin{array}{c}\text { Poisson } \\
\text { ratio }\end{array}$ & $\begin{array}{c}\text { Shear modulus }( \\
\text { Mpa })\end{array}$ & $\begin{array}{c}\text { Density } \\
\left(\mathrm{kg} . \mathrm{m}^{-3}\right)\end{array}$ \\
\hline Glass & 0.23 & 2.8 & 2460 \\
\hline Rubber & 0.49 & 2.9 & 1000 \\
\hline Steel & 0.25 & 1 & 5000 \\
\hline
\end{tabular}

The EDEM time step is set for $35 \%$. Data write time interval is set for the $0.005 \mathrm{~s}$. Grid size is $11 \mathrm{Rmin}$.

The radius of the particle used in simulation is $4 \mathrm{~mm}$, local volume factor is not more than $10 \%$, In the FluentEDEM scheme panel, select Lagrangian [7] as the coupling method. Set the sample points to 10 , set the momentum relaxation factor to 0.7, Auto- save case and data frequency is 50, at a time step of $0.001 \mathrm{~s}$, data files are saved every 0.05 $\mathrm{s}$, Set the Number of Time Steps to 1500. The simulation will run through $1.5 \mathrm{~s}$ of simulated time.

You can change the size of wind speed and wind angle to get the best separation effect in FLUENT.

\section{THE ANALYSIS OF SIMULATION RESULTS}

In the direction of the wind angle is zero, the selected velocity for $10 \mathrm{~m} / \mathrm{s}, 12 \mathrm{~m} / \mathrm{s}, 15 \mathrm{~m} / \mathrm{s}$, respectively for winnowing coupling experiment. A small amount of particles due to the collision with collecting groove edge will produce irregular displacement, it is necessary to modify the particle statistics, and get the horizontal coordinate distribution of the two kinds of particles in the collecting tank. Two particles in the 
collecting tank and horizontal coordinate distribution diagram as shown in Fig. 3, 4, and 5.

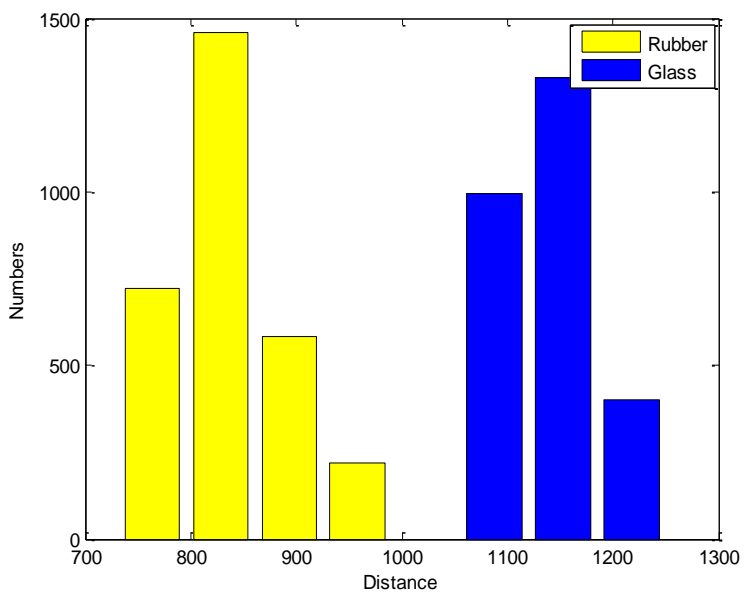

Fig. 2 Horizontal coordinates distribution of wind speed at 10

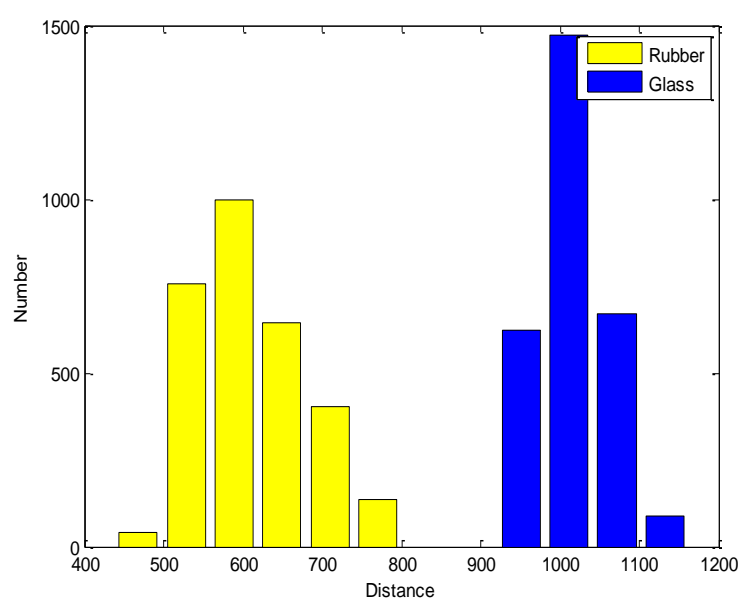

Fig. 3 Horizontal coordinates distribution of wind speed at 12

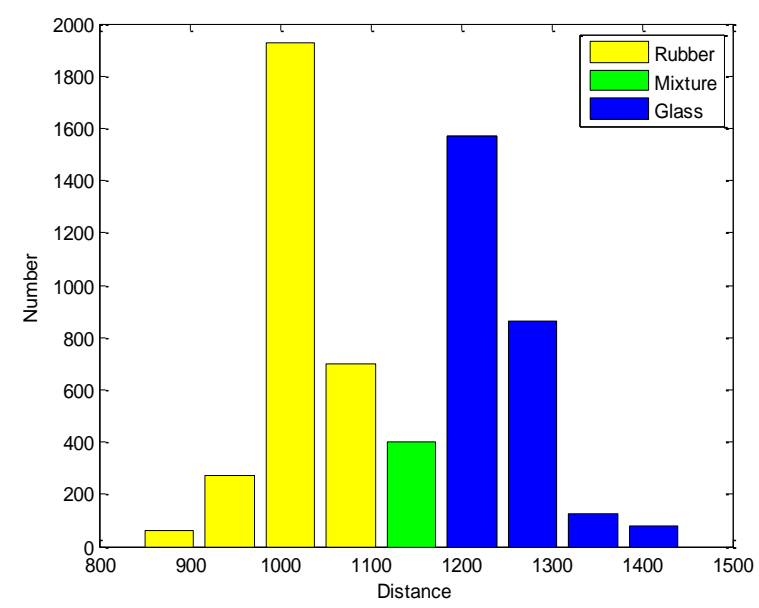

Fig.4 Horizontal coordinates distribution of wind speed at 15
According to Fig. 2, Fig. 3, Fig. 4 analysis can be found at wind speeds of $10 \mathrm{~m} / \mathrm{s}$, The distance between the two particles groups in the collecting tank is about $80 \mathrm{~mm}$., at the wind speed $12 \mathrm{~m} / \mathrm{s}$ it can be reached $210 \mathrm{~mm}$. Wind speed at the time of $15 \mathrm{~m} / \mathrm{s}$, because the wind speed is too large, particle trajectory divergence, there will be a part of mixing area, did not achieve the purpose of separation.

Consider wind angle influencing on the separation of particles. Select the wind speed $12 \mathrm{~m} / \mathrm{s}$, wind angle is 15 degrees, 20 degrees and 30 degrees to count the particles Groups distance, Groups width and Median distance difference, thus to analyze the best sorting direction angle. Survey results are shown in table 3 .

TABLE 3 COMPARISON OF PARAMETERS FOR DIFFERENT INCLINED ANGLES

\begin{tabular}{|c|c|c|c|}
\hline Angel & Groups distance & Groups width & Median distance \\
\hline 15 & 200 & 280,300 & 550 \\
\hline 20 & 240 & 350,280 & 600 \\
\hline 30 & Mixing area appear & & \\
\hline
\end{tabular}

Displayed by the simulation, when the wind speed is selected to $12 \mathrm{~m} / \mathrm{s}$, wind direction is 20 degrees, effect of separation is the best. Figure 5 is the simulated renderings.

( black particle represents glass, green represents rubber)

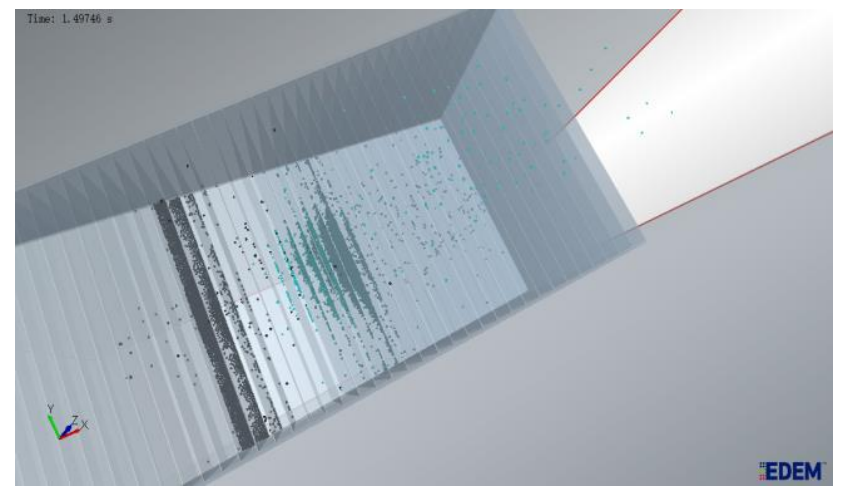

Fig.5 Simulated renderings of separation

\section{CONCLUSION}

Through research and analysis, breaking glass and rubber particles in the sorting process, as the wind speed increases, both granular pile horizontal distance be larger, sorting results get better and better. When the wind speed is $12 \mathrm{~m} / \mathrm{s}$, separation effect is ideal. When wind speed over $15 \mathrm{~m} / \mathrm{s}$, two particles cross, separation fail. In the case of wind speed is 12, When the wind angle is inclined upward 20 degrees compared with the horizontal direction. Two groups distinction is more obvious, and the single particle group is more concentrated. This is the most effective approach.

\section{ACKNOWLEDGEMENT}

Science \& Technology Pillar Program of Jiangsu Province (No. BE2013060). Key Project of Natural Science Research of Higher Education Institutions of Jiangsu Province (No. 
15KJA460001). Postdoctoral Research Program of Jiangsu Province (No.1401071C).

\section{REFERENCES}

[1] X.Yang and C.Lv, "Kinematic properties and test of plastics optimal separation equipment".Chinese Journal of Mechanical Engineering", 43 (2) : 132-135, 2007.

[2] J. Gao, "The Theoretical Research on Aspiration Efficiency and Air Current Directions".Journal of Wuhan Grain Industry College, (2) 36-40, 1993.
[3] G. Hu, "Analysis and Simulation of particle system by discrete element method". Wuhan University of Technology Press,7:142-143,2010.

[4] H. Liu. "Hydromechanics".China Architecture \& Building Press,96-98.2004.

[5] L. Shi, J. Wu and W. Zhao, " "The numerical simulation for corn curtain roller drying box based on CFD-EDEM coupling". Agricultural Research in the Arid Areas",32 (6):274-276,2014.

[6] E. Jiang ,Z. Sun and Z. Pan, “ Numerical Simulation Based on CFDDEM and Experiment of Grain Moving Laws in Inertia Separation Chamber". Transactions of the Chinese Society of Agricultural Engineering,45 (4):118-120,2004.

[7] G. Wang, W. Hao, and J. Wang, "Discrete element method and its application in EDEM", Northwestern Polytechnic University Press, 104-108,2010. 